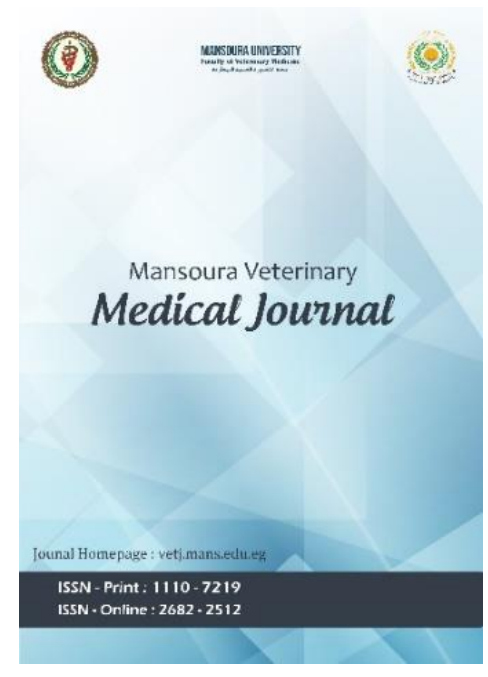

\title{
Induction of Surgical Obstructive Cholestasis in rats: morphological, biochemical and immunohistochemical changes
}

Nermeen Elsaied, Alaa Samy, Esam Mosbah, Adel Zaghloul

To cite this article: Nermeen Elsaied, Alaa Samy, Esam Mosbah, Adel Zaghloul. Induction of Surgical Obstructive Cholestasis in rats: morphological, biochemical and immunohistochemical changes. Mansoura Veterinary Medical Journal 2020; 21, 3: 107-115.

To link to this article: https://doi.org/10.35943/mvmj.2020.21.318 Published online: 29 September 2020

Submit your article to this journal

CrossMark data 


\section{Induction of Surgical Obstructive Cholestasis in rats: morphological, biochemical and immunohistochemical changes}

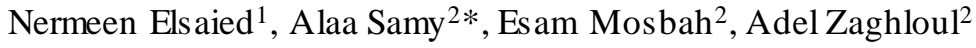

${ }^{1}$ Veterinarian, Dakahlia, Egypt

${ }^{2}$ Department of Surgery, Anesthesiology, and Radiology, Faculty of Veterinary, Medicine, Mansoura University, 35516 Mansoura, E gypt

\section{ARTICLE HISTORY}

Received: 05.04.2020

Revised: 19.07.2020

Accepted: 20.07.2020

Address correspondence to Alaa Samy; Tel: +201014302034; E-mail:

alaasamy_vet2006@yahoo.com, ORCID 0000-0001-5332-9828

\section{ABSTRACT}

\begin{abstract}
Objective: To detail an easy approach for surgical induction of obstructive cholestas is in a rat model. Additionally, to assess the role of serum and tissue biomarkers for determination of the extent of cholestasis induced hepatocellular injury and to quantify the apoptotic liver cell using fluorescein-labeled Annexin V.

Design: Randomized controlled experimental study.

Animals: Sixty-five healthy Male Sprague- Dawley rats weighing $268.18 \pm 23.3$ grams. Procedures: The rats were randomly allocated into two main groups: 1) sham group (SO; $n=15)$ and 2) bile duct ligation group (BL; $n=50)$. Three SO rats and 8 BL rats were euthanized at 10, 20,30, 45 and 60 post-surgery. Blood and liver samples were collected for serum and tissue biochemical analysis. Liver apoptosis was quantified using Annexin $V$, meanwhile liver fibrosis was quantified using both TNF- $\beta$ and histological examination.

Results: There was a tendency towards less complications and higher surgeon satisfaction when the common bile duct was approached by the stomach approach. Serum biochemical analysis revealed a significant time-dependent decreases in hepatic serum biomarkers (alanine aminotransferease, aspartate aminotransferase, serum glutamic oxaloacetic transaminase, alkaline phosphatase, gamma-glutamyltransferase, serum albumin, the concentration of total bilirubin, and direct bilirubin) after induce $d$ obstructive cholestasis ( $P=0.01-0.001)$, whereas AST: ALT ratio conversely was elevated ( $p<0.05$ value). Flow cytometer analysis revealed time-dependent significant increase in the percent of apoptotic cells after $\mathrm{BL}(\mathrm{P}<0.001)$ and consequently the state of oxidative stress (malondialdehyde) was $(P<0.001)$. The antioxidant tissue markers (superoxide dismutase, Catalase and glutathione reductase) were significantly decreased $(P<0.05)$, meanwhile TNF- $\beta$, the fibrosis marker showed time dependent significant increases $(P=0.001)$.

Conclusion and clinical relevance: Stomach approach provided an easy, fast and reliable procedure for induction of obstructive cholestasis in rats. Liver Annexin $V$ and TGF- $\beta$ were diagnostic tools in further apoptosis and fibrosis.
\end{abstract}

Keywords: Bile duct ligation, Liver, Antioxidants, Annexin V, TGF- $\beta$.

\section{INTRODUCTION}

Obstructive cholestasis is a bile flow stagnation, which may result from a failure in the secretory transport in the hepa tocytes or in the ductular cells, or from blocking in the free bile flow excretory pathway outside the liver [1]. Experimental induction of obstructive cholestasis by bile duct ligation (BDL) in rodents has been used for a long time as a reliable model for cholestatic liver diseases for investigating ongoing hepatic insults due to cholestasis. Most of these earlier studies in rodents only allowed a nimals to be kept for short periods wi th high mortalities, because of infections and other surgery-associated complications [2]. As a result, further subsequent studies were directed towards obviating the observed complications. Tag et al.[3] emphasized BDL model surgery performed by an experienced scientist has very high reproducibility among all fibrotic models, nevertheless, this model can result in significant variations when surgery is carried out by untrained personnel or when unconscious modifications are implemented that affect the quality of the intervention.

Liver fibrosis basicallyis a late event healing response in chronic liver injuries [4]. It is characterized by excessive production and accumulation of collagen and extracellular matrix proteins originate from a complexnetwork of hepatic stellate cells (HSC), va rious liver-resident cells a nd i nfiltrating 
blood cells and can progress into liver cirrhosis and even hepatocellular carcinoma [5].

Independent of etiology, the molecular mechanisms underlying hepatic fi brosis a re very similar. Following hepatic injury, a highly orchestrated program of molecular and cellular changes is initiated [6]. It includes membrane blebbing, nuclear chromatin condensation, cell shrinkage, chromosomal DNA fragmentation, and apoptotic cells die in a controlled and regulated fashion [7].

Liver pathology is very complex and differential diagnosis is sometimes difficult to achieve. Along with biopsy and imaging techniques, serum biomarkers have an important role in managing patients with different liver disorders [8]. Researchers are trying to understand the pathogenic mechanisms of acute and chronic hepatic failure ongoing hepatic fibrosis. Therefore, experimental models have been generated that mimic various aspects of the complex mechanisms that lead to hepatic inflammation, fibrosis, and cirrhosis [9]. Surgical ligation of the common bile duct has become the most commonly used model to study the molecular and cellular events that underlie these pathophysiological mechanisms induced by inappropriate bile flow [6].

Many studies on humans and animals showed a close correlation between lipid peroxidation and antioxidant enzyme activities with the development of liver injury after extra-hepatic cholestasis in rats [10]. During acute and chronic liver injury, transforming growth factor (TGF- $\beta$ ) is activated from deposits in the ECM, expressed and released from various cell types [11]. Phagocytosis of a poptotic bodies promotes the generation of TGF- $\beta$, a cytokine with potent pro-fibrogenic and pro-apoptotic activity in the liver and this process is associated with activation of quiescent HSC; a key event in hepatic fibrosis. HSCs undergo apoptosis during fibrosis reversal [12]. Therefore, the clearance of activated HSCs by apoptosis is critical for the reversibility of fibrosis [11]. Annexin V is commonly used to detect a poptotic cells by its ability to bind to phosphatidylserine, a ma rker of apoptosis when it is on the outer leaflet of the plasma membrane [13]. It is clear that there is an urgent need for novel strategies allowing early diagnosis of this disease [5]. Thus, in light of the above-mentioned facts, the objective of the present study was to detail an easy and satisfying applicable protocol for BDL for experimental surgical induction of obstructive chol estasis in the rat model. Additionally, to discover the role of serum and tissue biomarkers for determination of the extent of cholestasis induced hepatocellular injury and to qua ntitate the apoptotic liver cell using fluorescein-labeled Annexin V.

\section{MATERIALS AND METHODS}

\subsection{Animals}

Sixty-five healthy Male Sprague-Dawley rats at 5- 6 months of age and weighting (mean \pm standard deviation) $268.18 \pm 23.3$ grams were used. Animals were housed at the
Surgery Department of Mansoura Veterinary Teaching Hospital, Mansoura University, Mansoura, Egypt, at a constant temperature (mean $22^{\circ} \mathrm{C}$, with standard deviation $1^{\circ} \mathrm{C}$ ) with a 12-hr: $12-\mathrm{hr}$ dark/light cycle, in the same unit. They were fed a standard rat chow and tap water. The animals were allowed to acclimatize to their new conditions for one week before the study began. The experimental protocol of this work was approved by Mansoura Local Ethical Committee.

\subsection{Experimental design}

The rats $(n=65)$ were randomly divided into two main groups: 1 ) sham-operated group (SO; $n=15)$ : rats subjected only to a routine laparotomy and 2 ) bile duct ligation group ( $B L ; n=50$ ) which was allocated according to the bile duct a pproach into 2 subgroups (25 rats of each): 1 ) Liver approach (LA) and 2) Stomach approach (SA) techniques

\subsection{Surgical procedures}

Anesthesia was achieved using an intraperitoneal injection of a mixture of ketamine $\mathrm{Hcl}$ (Ketalite 5\%, ELICE PHARMA, Pakistan) at dose $75 \mathrm{mg} / \mathrm{kg}$ and xylazine $\mathrm{Hcl}$ (xylaject 2\%, Adwia pharmaceutical company, Egypt) at dose $5 \mathrm{mg} / \mathrm{kg}$ in the same syringe. Under complete aseptic conditions and after a mid-line laparotomy starting from the xiphoid ca rtilage was performed, obstructive cholestasis was induced following identifying the bile duct using two approaches 1) The liver approach (LA technique) was conducted according to Sokol et al. [14] and Tag et al. [3]. Briefly, the liver was lifted with a moisturized $(0.9 \% \mathrm{NaCl}$ solution) sterile cotton swab so that the ventral side of it sticks to the diaphragm and the hilum is clearly visible. The bile duct was exposed by caudal movement of the gut, separated carefully from the fla nking portal vein and hepatic artery (Figure. 1A) using small artery forceps.

2) The stomach approach (SA technique), the stomach was exteriorized using the back of tissue forceps, and then the duodenum was grasped. The bile duct was carefully identified (without separation) from the flanking portal vein and hepatic artery byits characterized white color and its passage (Figure 1B).

Regardless of the techniques used for identification of the bile duct, double ligations with $1 \mathrm{~cm}$ apart were applied along the bile duct using 5-0 size polypropylene suture material. Bile duct was transected in between ligations. The exteriorized organs were re-adjusted back to its sites, and the peritoneal cavity was rinsed with $0.9 \% \mathrm{NaCl}$ solution. Celi otomy incision was closed routinely. After recovery, rats received a meloxicam (meloxicam 15mg, AMRIYA pharmaceutical company, Egypt) in a dose of $5 \mathrm{mg} / \mathrm{kg}$ for 3 days. Antibiotic regimen included Cefotaxime sodium (Cefotaxime sodium, EIPICO pharmaceutical company, Egypt) at dose $50 \mathrm{mg} / \mathrm{kg}$ for 3 days.

Both techniques used for conduction of bile ducts were assessed using: the length $(\mathrm{cm})$ of the mid-line celiotomy incision that was suitable to identification of the commonbile 
duct, liver damage score (0: no damage, 1: low degree and 2 high degree), the bleeding score (0: minute bleeding, 1 : medium bleeding and 2: perfuse bleeding), the level of surgeon satisfaction (0: bad, 1: a verage and 2: good) and the mortality rate (\%). Rats were kept under observation then three $S O$ rats and eight BL rats were eutha nized at 10, 20, 30, 45 and 60 postoperative days.

\subsection{Laboratory examination}

\subsubsection{Samples collection}

For serum biochemical examination, cardiac blood sa mples were collected in plain tubes without anticoagulants under sterile conditions using 18 gauge needl es with a $10 \mathrm{ml}$ attached syringe. Through the portal vein, the liver was perfused (Figure 2A) slowly in its position with $20-25 \mathrm{ml}$ sterile phosphate buffer saline solution using 21 ga uge scalp till obtaining a pale-colored swollen liver free fromblood and ready for further examinations.

\subsubsection{Biochemical serum analysis}

Serum was used to evaluate the activity of serum alanine aminotransferease (ALT), as partate aminotransferase (AST), alkaline phosphatase (ALP), gamma-glutamyltransferase (GGT), serum albumin (SA), the concentration of total bilirubin (TB), and direct bilirubin (DB) by automated standardized procedures using biochemistry analyzer (Robonic suction spectrophotometer, India) using special kits.

\subsubsection{Biochemical hepatic tissue analysis}

Liver samples were collected in a sterile aluminum foil and preserved at $-40{ }^{\circ} \mathrm{C}$ for biochemical estimation of antioxidants: superoxide dismutase (SOD), Catalase, glutathione reductase (GSH) and oxidative factor malondialdehyde (MDA) by automated standardized procedures (Robonic suction spectrophotometer, India) using ready diagnostic (Biodiagnostic, Egypt) kits [21, 22].

\subsubsection{Immunohistochemical examination}

Liver samples were collected in sterile eppendorfs and preserved at liquid nitrogen tanks at $-40{ }^{\circ} \mathrm{C}$ for further estimation of the apoptotic marker Annexin V $[15,16]$; and the marker of hepatic stellate cell activation (transforming growth factor- $\beta$; TGF- $\beta$ ) [17] using BD Accuri C6 flow cytometer (BD Biosciences, San Diego, USA).

\subsubsection{Histopathological examination:}

Liver samples were fixed with $10 \%$ buffered formalin solution, dehydrated in graded ethanol, and then embedded in paraffin wax. Five $\mu$ m-thick paraffin-embedded sections were cut and routinely stained with hematoxylin and eosin. Other tissue sections were stained by Masson trichrome stain [18] to investigate the collagen fibers and degree of fibrosis.

\subsubsection{Measurement of Fibrosis score}

Development of liver fibrosis was semi-quantitatively assessed based on liver histology evaluated by a blinded pathol ogist using Huss scoring system [19] in which periportal fibrosis was staged from 0-4 and perisinusoidal fibrosis from $0-2$, giving a maximum value that was equivalent to cirrhosis of 6 .

\subsubsection{Statistical analysis}

Statistical analysis was performed using SPSS (version 23.0, Inc, USA). Sample T tes t was used to compare means of incisions between the two techniques. Differences in frequency of mortality were statistically evaluated using Fisher Exact test. Non parametric Mann-Whitney $U$ test was used to compare liver damage, bleeding, and surgeon satisfaction scores between the two operated techniques. Scores were presented as median (range). Descriptive statistics were calculated in the form of Mean \pm Standard deviation (SD). In the statistical comparison between the different groups, the significance of differences was tes ted using one wayANOVA (a nalysis of variance) followed by posthoc Tukey. A P value $<0.05$ was considered statistically significant.

\section{RESULTS}

\subsection{Clinical findings}

The length (mean \pm SD) of the mid-line laparotomy incision of both the skin and the cutis which was a ppropriate for approaching the common bile duct using SA $(2.27 \pm 0.25$ $\mathrm{cm})$ was significantly $(P=0.00)$ lower than that of the LA (3.38 \pm 0.34 ). From the viewpoint of the level of surgeon satisfaction (median (range)) for induction of obstructive cholestasis, it was significantly $(P=0.00)$ higher when the common bile duct was a pproached through SA (2.0 (1.0 -2.0)) compared to that approached though LA technique (0.5 (0.0$0.2)$ ). With $L A$, surgeon manipulation resulted a significant $(P$ $=0.00)$ liver damage $(1.0(1.0-2.0))$ compared with SA $(0.0$ (0.0-0.0)). Consequently, liver bleeding was significantly $(P=$ $0.000)$ higher in rats operated with LA (1.5 (1.0-2.0)) compared to that's operated by SA technique (0.0 (0.0-1.0)). A higher mortality rate $25 \%$ was observed in rats operated with LA meanwhile all rats operated with SA technique succumbed operation without mortality (Table 1).

Jaundice was observed in $B L$ rats on the first $(59 \%$ of $B L$ rats), and second ( $61 \%$ of $B L$ rats) postoperative days. Signs of jaundice continued for $3.45 \pm 0.68$ days and completely disappeared before the eighth postoperative day. Healing of the incisions incholesta tic rats was accomplished within $12 \pm$ 2.12 days meanwhile, it occurred in $4.5 \pm 1.3$ days in SO group. Abdominal distension (ascites) was observed in $\mathrm{BL}$ rats after the $24.7 \pm 1.4$ postoperative days. 
Table 1. The results of the common bile duct approaching techniques after induction of bile duct ligation in rats.

\begin{tabular}{cccccc} 
& $\begin{array}{c}\text { Incision } \\
\text { length }\end{array}$ & $\begin{array}{c}\text { Liver } \\
\text { damage }\end{array}$ & Bleeding & $\begin{array}{c}\text { Surgeon } \\
\text { satisfaction }\end{array}$ & $\begin{array}{c}\text { Mort- } \\
\text { ality }\end{array}$ \\
\cline { 2 - 6 } & $\mathrm{cm}$ & score & score & score & $\%$ \\
LA & $3.38 \pm$ & $1.0(1.0-2.0)$ & $1.5(1.0-2.0)$ & $0.5(0.0-0.2)$ & 25 \\
$(\mathrm{n}=25)$ & 0.34 & & & & \\
$\mathrm{SA}$ & $2.27 \pm$ & $0.0(0.0-0.0)$ & $0.0(0.0-1.0)$ & $2.0(1.0-2.0)$ & 0 \\
$(\mathrm{n}=25)$ & 0.25 & & 0.000 & 0.000 & 0.000 \\
$\begin{array}{c}P \\
\text { value }\end{array}$ & 0.000 & 0.000 & 0.000
\end{tabular}

LA: Liver approach

SA: Stomach

Approach

Incision was presented as mean \pm SD

as median (range)

\subsection{Animal necropsy}

Bodyweight showed a slight and non-significant increase after 10 days from $B L(B L 10)$ a bout $11.5 \pm 2.28$ (7.5\%), then it showed a significant $(P<0.05)$ time dependent increases

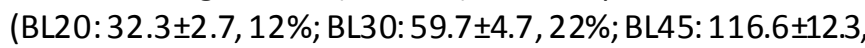
$42.9 \%$ and $B L 60: 130 \pm 18.3,49.4 \%)$. The liver a ppeared dark congested, slightly enlarged and turgid in its consistency in both BL10 and BL20 groups. There was a significant progressive increase in liver weight with time starting from BL30 and the liver was paler with distended ligated common bile duct (Figure 2B). Viscous yellow color fl uid was observed and filled the abdomen of rats in BL45 and BL60 groups.

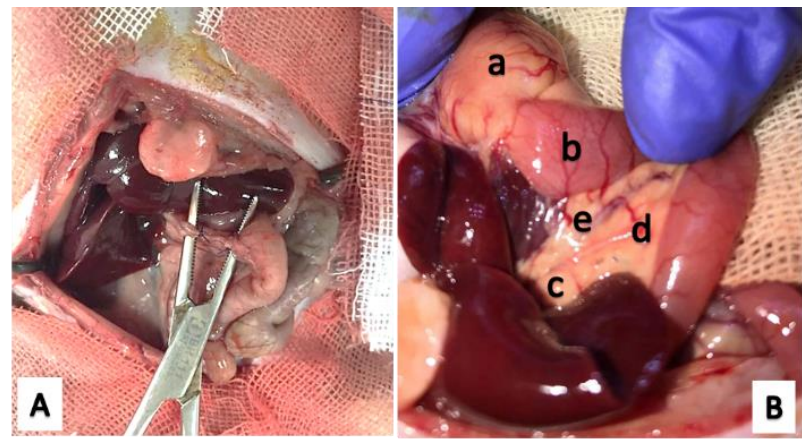

Figure 1. The two techniques used for approaching the bile duct in rats. $\mathbf{A}$; LA (Liver Approach) technique was operated according to Sokol et al. [20]. Note the separation of the bile duct. B; SA (Stomach Approach) a technique operated for identification of the common bile duct. (a: stomach; b: duodenum; c: the ventral side of the liver; d: bile duct (white color) and e: portal vein).

\subsection{Biochemical serum analysis}

After BL, liver serumbiomarkers (Table 2) ALT, AST, ALP, GGT, albumin, total bilirubin, direct and indirect bilirubin, showed a time dependent significant $(P<0.05)$ gradual decrease in their levels. Meanwhile, AST: ALT ratio conversely was elevated ( $p<0.05$ value).

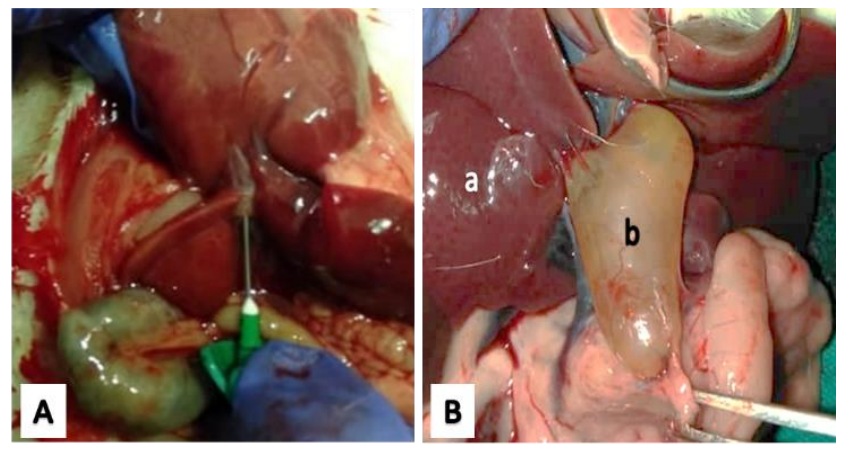

Figure 2. Livers of BL rats. A; the liver was perfused in its position throug $h$ the portal vein (arrow) with phosphate buffer saline solution using 21 gauge scalp. B; necropsy of a rat from group BL60, the liver (a) was paler in color with a distended ligated common bile duct (b).

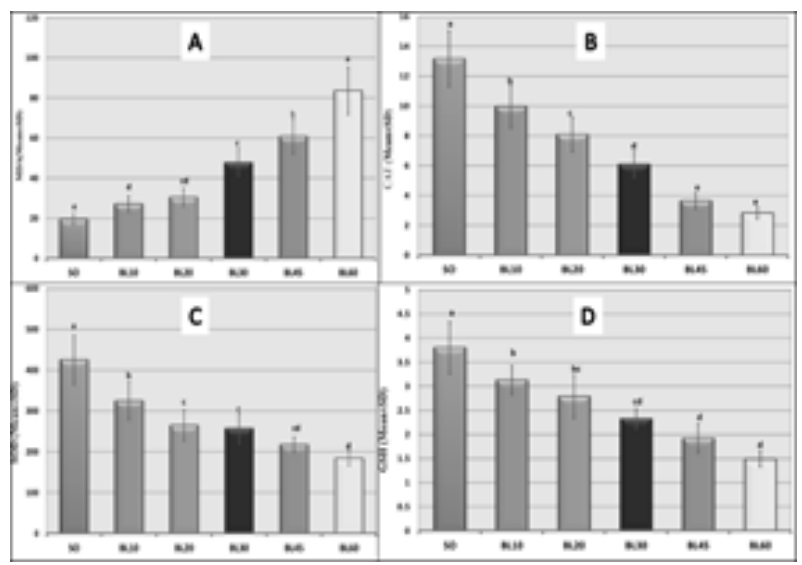

Figure 3. Biochemical tissue analysis (A: MDA, B: CAT, C: SOD and D: GSH) between sham operated and bile duct ligated rats.

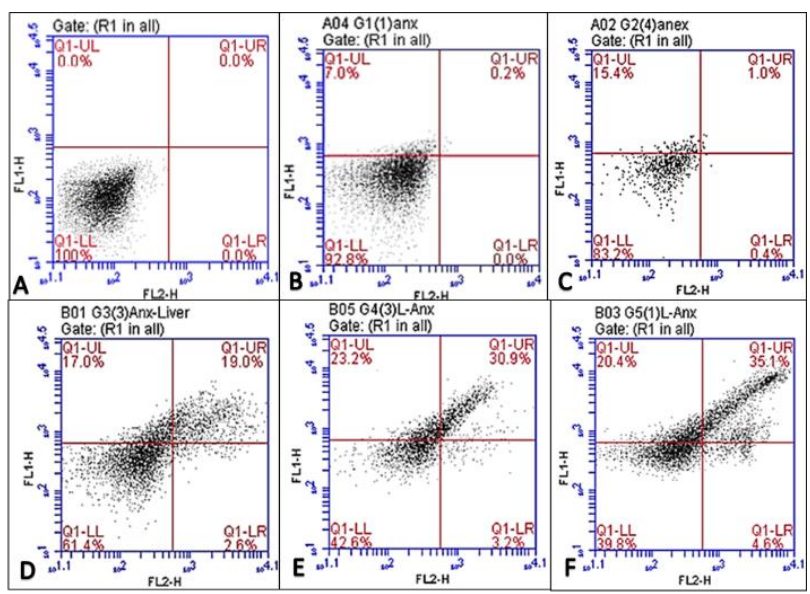

Figure 4. Annexin $V$ results (the quantity of apoptosis) for hepatic tissues from sham operated and bile duct ligated rats. A: SO group, B: BL10 group, C: BL20 group, D: BL30 group, E: BL45 group, and F: BL60 group. Q1-LL: live cells; Q1-LR: apoptotic cells; Q1-UR: dead cells and Q1-UL late apoptotic cells.

\subsection{Biochemical hepatic tissue analysis}

The oxidative stress and antioxidant markers showed remarkable changes compared to the SO group. There were significant time dependent increases in MDA level (Figure 3A) after $B L$ except in group BL10 ( $<<0.05)$. Catalase enzyme showed significant decreases in its level corresponding to the 
duration of BL (Figure 3B). There was a non-significant difference between the BL 45 group and the BL60 group in the level of CAT. There was a gradual significant decrease in SOD enzyme (Figure 3C) and GSH values (Figure 3D) in a reverse proportionality to the duration of $\mathrm{BL}$ with a non-significant difference between BL20 group and BL30 group in the level of SOD and a non-significant difference between BL45 group and BL60 group in the level of GSH.
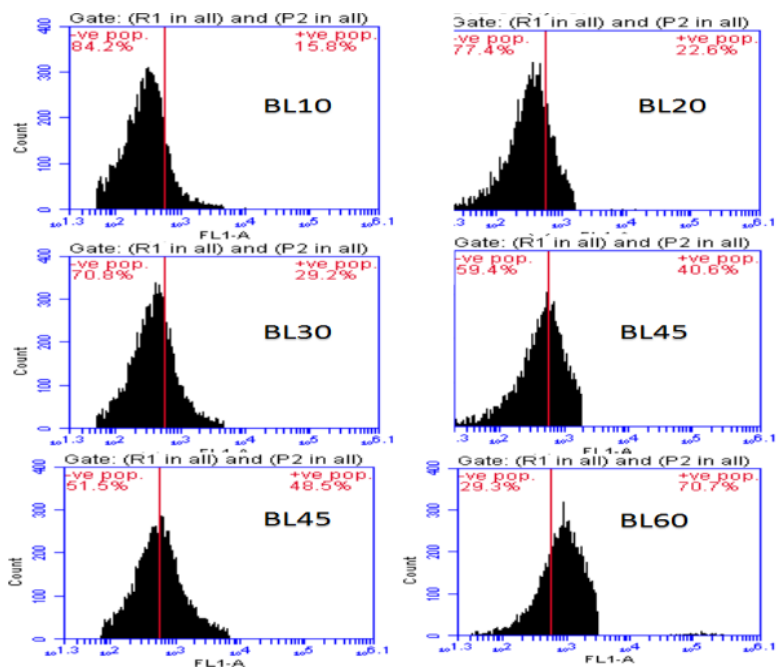

Figure 5. shows the results of positive TGF- $\beta$ (+ve pop) the fibrosis marker, which increased gradually from the BL10 group to reach $70.7 \%$ of the total liver tissue cells in the BL60 group. Negative TGF- $\beta$ (-ve pop) decreased gradually along groups.

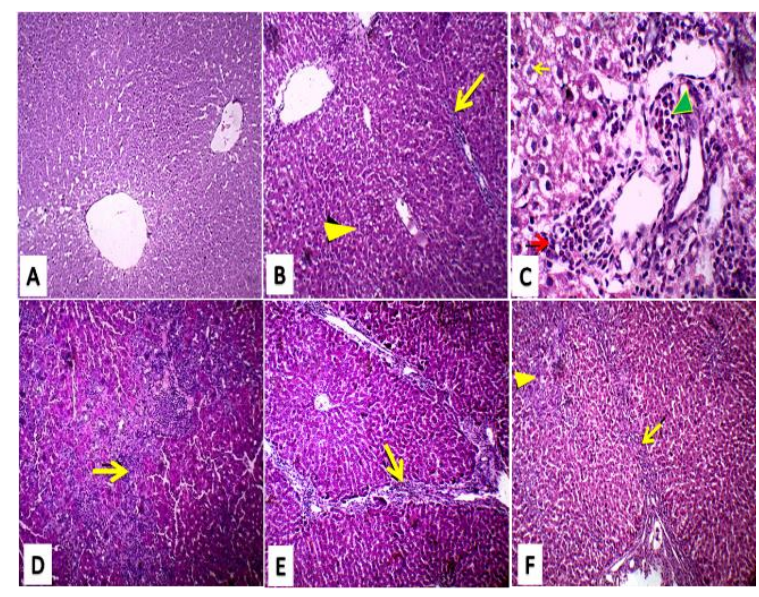

Figure 6. Histopathological findings of the liver of both sham operated and bile duct ligated rats (H\&E 100x). A: in SO group, it displays normal hepatocytes and normal hepatic architecture with normal central vein. B: in the BL10 group, it displays extensive infiltration of the portal area with, lymphocytes (arrow), and vacuolar degeneration of hepatocytes (arrowhead) and mild fibroblastic proliferation extending from portal area. C: in the BL20 group, portal area infiltrated with, lymphocytes (arrowhead), epithelioid cells (red arrow), neutrophils and plasma cell recruitment (yellow arrow). D: In the BL30 group, there was extensive necrosis of hepatocytes with marked chronic hepatitis represented by aggregation of lymphocytes and macrophages in hepatic lobule (arrow). E: in the BL45 group, there was intralobular fibroblastic proliferation extending from portal area forming complete thick porto-portal bridging fibrosis with a tendency to form cirrhotic nodules (arrow). F: in the BL60 group, there was extensive intralobular fibroblastic proliferation forming bridging fibrosis with replacement of hepatic parenchyma with fibrous tissue (arrowhead) and fibro-collagenous proliferation on hepatic surface (arrow).

\subsection{Immunohistochemical examination}

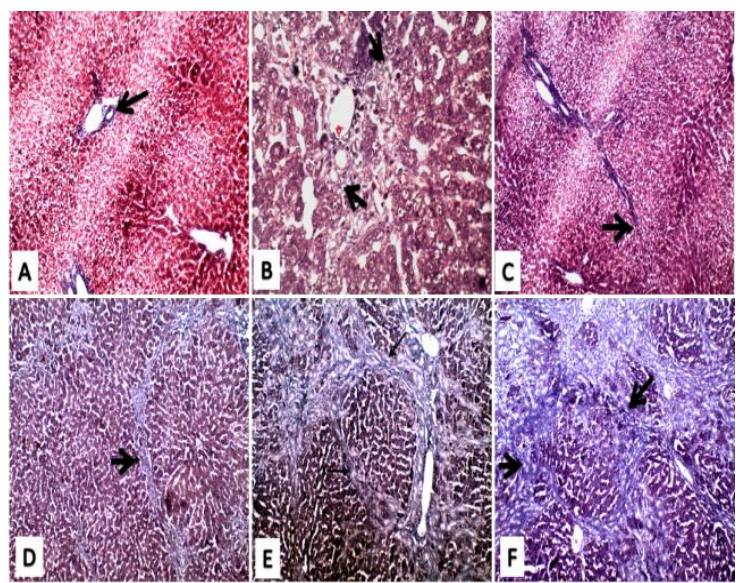

Figure 7. Histopathological findings of the liver of both sham operated and bile duct ligated rats (Masson trichrome stain, $100 \mathrm{x}$ ). A: SO group, normal hepatic architecture with fibrous tissue limited to major vessels in the portal area (arrow). B: BL10 group, mild bluish stained fibrous tissue forming arborizing patterns around the portal area (arrow). C: BL20 group, bluish stained incomplete porto-portal bridging fibrosis (arrow). D: BL30 group, bluish stained complete thin porto-portal bridging fibrosis (arrow). E: BL45 group, bluish stained complete thick intralobular bridging (arrow) with a tendency to form cirrhotic nodules. F: BL60 group, bluish stained complete thick porto-portal (intralobular) bridging fibrosis with a tendency to form cirrhotic nodules (arrow).

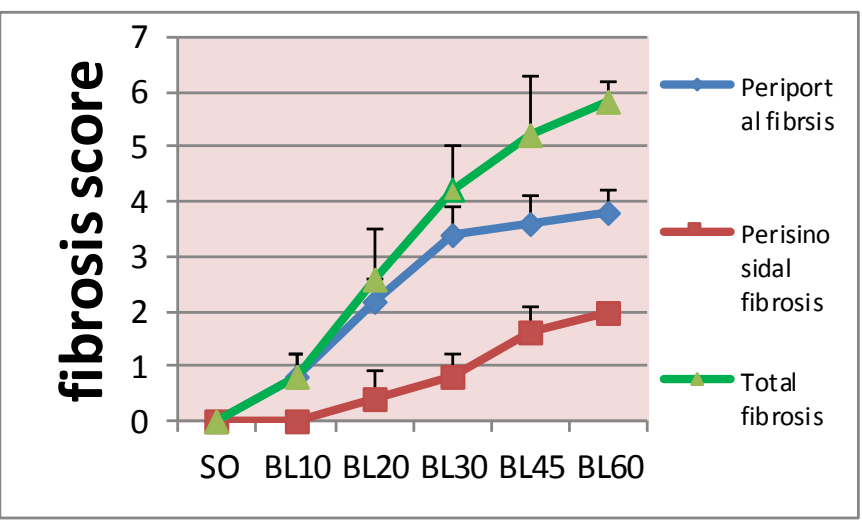

Figure 8. Liver fibrosis scores of both sham operated and bile duct ligated rats

Flow cytometer analysis (Table 2 and Figure 4) using Annexin Vantibody revealed that BLinduced time dependent a poptosis in hepatic cells. In BL10, cells s howed $7 \%$ apoptotic cells (Annexin UL), which increased gradually to be $20.4 \%$ in BL60. TNF- $\beta$, the fibrosis marker, showed time dependent significant increases (Figure 5) after BL. There was a nonsignificant difference between groups $B L 20$ and $B L 30$ in the level of positive TNF- $\beta$. There were significant decreases in the level of negative TNF- $\beta$ in a reverse correlation to the duration of BL.

\subsection{Histopathological examination}

\subsection{1. $H$ and $E$ stain}

Normal hepatocytes, hepatic architecture, and central vein were displayed in the SO group (Figure 6a).Extensive 
infiltration of the portal area with Iymphocytes, vacuolar degeneration of hepatocytes and mild fibroblastic proliferation, extending from the portal area, were noticed in the BL10 group (Figure 6b).There were Iymphocytes, epithelioid cel ls, neutrophils and plasma cell recruitment in the portal area in the BL20 group (Figure $6 \mathrm{C}$ ). In the BL30 group, the liver displayed extensive necrosis of hepatocytes with marked chronic hepatitis repres ented by a ggregation of lymphocytes and macrophages in hepatic lobule (Figure 6D). The liver in the BL45 group displayed intralobular fibroblastic proliferation extending from portal a rea forming complete thick porto-portal bridging fibrosis with a tendency to form cirrhotic nodules (Figure 6E). Mea nwhile, in the BL60 group, hepatic parenchyma was replaced with fibro-collagenous tissue and intra-lobular fibroblastic proliferation extending from portal area forming complete thick porto-portal bridging fibrosis with a tendency to form cirrhotic nodules. There was fibro-collagenous proliferation on the hepatic surface (Figure 6F).

Table 2. Results of serum biochemical analysis and flow cytometer:

\begin{tabular}{|c|c|c|c|c|c|c|c|}
\hline \multirow{2}{*}{\multicolumn{2}{|c|}{ Variable \pm SD }} & \multicolumn{3}{|c|}{ Time post-treatment (day) } & \multirow[b]{2}{*}{ BL30 } & \multirow[b]{2}{*}{ BL45 } & \multirow[b]{2}{*}{ BL60 } \\
\hline & & so & BL10 & BL20 & & & \\
\hline \multirow{9}{*}{$\begin{array}{l}\frac{n}{0} \\
\frac{n}{\pi} \\
\frac{0}{0} \\
\frac{\pi}{0} \\
\frac{0}{E} \\
\frac{d}{U} \\
\frac{0}{0}\end{array}$} & $\operatorname{ALT}(\mathrm{U} / \mathrm{L})$ & $36.0^{\mathrm{d}} \pm 4.9$ & $158.8^{a} \pm 22.7$ & $113.1^{b} \pm 16.2$ & $69.0^{c} \pm 9.9$ & $60.0^{c} \pm 8.6$ & $46.8^{c d} \pm 6.7$ \\
\hline & AST (U/L) & $34.0^{\mathrm{e}} \pm 5.0$ & $328.8^{a} \pm 46.9$ & $258.0^{b} \pm 36.9$ & $206.6^{c \pm 31.2}$ & $176.8^{\mathrm{cd}} \pm 25.3$ & $158.7^{d} \pm 22.7$ \\
\hline & AST/ALT ratio & $0.9^{d} \quad \pm 0.2$ & $2.3^{c} \pm 0.4$ & $2.7^{c} \pm 0.2$ & $3.43^{\mathrm{b}} \quad \pm 1.8$ & 5. $7^{\mathrm{a}} \quad \pm 1.4$ & $2.5^{c} \pm 1.6$ \\
\hline & Total bilirubin (mg/dL) & $0.9^{e} \pm 0.1$ & $3.8^{a} \pm 0.6$ & $2.5^{b} \pm 0.4$ & $2.20^{\mathrm{bc}} \pm 0.31$ & $1.9^{\mathrm{cd}} \pm 0.3$ & $1.7^{d} \pm 0.3$ \\
\hline & Direct bilirubin (mg/dL) & $0.2^{d} \pm 0.0$ & $1.3^{a} \pm 0.2$ & $0.9^{b} \pm 0.1$ & $0.8^{\mathrm{b}} \pm 0.1$ & $0.6^{c} \pm 0.1$ & $0.6^{c} \pm 0.1$ \\
\hline & Indirect bilirubin (mg/dL) & $0.7^{c} \pm 0.1$ & $2.6^{a} \pm 0.4$ & $1.6^{b} \pm 0.2$ & $1.6^{b} \pm 0.2$ & $1.3^{b} \pm 0.2$ & $0.9^{\mathrm{e}} \pm 0.1$ \\
\hline & Albumin $(\mathrm{g} / \mathrm{dL})$ & $4.4^{a} \pm 0.6$ & $3.4^{b} \pm 0.5$ & $2.9^{b c} \pm 0.4$ & $2.7^{c} \pm 0.4$ & $1.8^{\mathrm{d}} \pm 0.3$ & $1.4^{d} \pm 0.2$ \\
\hline & $\operatorname{ALP}(U / L)$ & $73.3^{e} \pm 10.5$ & $1916^{a} \pm 273.7$ & $1575.0^{b} \pm 225.0$ & $561.7 c \pm 80.2$ & $241.8^{d} \pm 34.5$ & $231.4^{d} \pm 33.1$ \\
\hline & GGT (U/L) & 8. $8^{f} \pm 1.3$ & $46.2^{a} \pm 4.6$ & $40.5^{b} \pm 5.4$ & $33.1^{c} \pm 4.7$ & $27.5^{d} \pm 4.5$ & $15.7^{\mathrm{e}} \pm 2.2$ \\
\hline \multirow{6}{*}{ 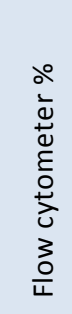 } & Annexin II (viable cells) & $100^{\mathrm{a}} \pm 0.6$ & $92.8^{\mathrm{ab}} \pm 0.5$ & $83.2^{b} \pm 0.4$ & $61.4^{c} \pm 0.4$ & $42.6^{d} \pm 0.3$ & $39.8^{\mathrm{d}} \pm 0.2$ \\
\hline & Annexin ur (dead cells) & $0.0 d \pm 0.0$ & $0.2 d \pm 0.1$ & $1.0^{d} \pm 0.1$ & $19.2^{c} \pm 1.6$ & $28.4^{b} \pm 4.1$ & $36.6^{a} \pm 5.2$ \\
\hline & $\begin{array}{l}\text { Annexin Ir (early } \\
\text { apoptosis) }\end{array}$ & $0.0^{d} \pm 0.0$ & $0.0^{d} \pm 0.0$ & $0.4^{d} \pm 0.0$ & $2.4^{c} \pm 0.3$ & $3.2^{b} \pm 0.5$ & $4.4^{\mathrm{a}} \pm 0.8$ \\
\hline & $\begin{array}{l}\text { Annexin ul (late } \\
\text { apoptosis) }\end{array}$ & $0.0^{f} \pm 0.0$ & $7.0^{e} \pm 1.7$ & $15.4^{d} \pm 2.3$ & $17.0^{c} \pm 2.9$ & $23.2^{b} \pm 3.2$ & $20.4^{\mathrm{a}} \pm 3.9$ \\
\hline & TGF- $\beta$ Positive & $0.8^{e} \pm 0.1$ & $19.2^{d} \pm 2.7$ & $30.4^{c} \pm 4.3$ & $34.4^{c} \pm 4.9$ & $44.6^{b} \pm 6.4$ & $66.3^{a} \pm 9.5$ \\
\hline & TGF- $\beta$ Negative & $98.9^{a} \pm 14.1$ & $80.8^{b} \pm 11.5$ & $69.7^{b c} \pm 9.9$ & $65.7^{\mathrm{cd}} \pm 9.4$ & $55.5^{d} \pm 7.9$ & $33.7^{e} \pm 4.8$ \\
\hline
\end{tabular}

Means $\pm S D$ with different superscript letters in the same row are significantly different at $P \leq 0.05$. SO: sham operated rats and BL: bile duct ligated rats. $\mathrm{SO}=$ sham operated rats. $\mathrm{BL}=$ bile duct ligated rats. $\mathrm{ALT}=$ Alanine Aminotransferease. $\mathrm{AST}=\mathrm{Aspartate}$ aminotransferase test. $\mathrm{ALP}=\mathrm{alkaline}$ phosphatase. $\mathrm{GGT}=$ gamma-glutamyltransferase. TGF $-\beta=$ transforming growth factor $-\beta$

\subsubsection{Masson trichrome stain}

The liver by Masson trichrome stainin the SO group exhibited grade 0 fibrosis with normal hepatic architecture and fi brous tissue limited to major vessels in portal area with (Figure 7A). In BL 10 group, the liver showed grade1 fibrosis, represented by mild bluish stained fibrous tissue forming an arborizing pattern and small stellated-expansions of the portal fields without the formation of septa (Figure 7B). Moreover, in BL20 group grade 2 liver fibrosis was observed and the fibrous tissue forming incomplete intra-lobular bridging from the portal tract to the central vein which do not interconnect with each other (Figure 7C).

Grade 3 fibrosis was observed in BL30 group, where the fibrous tissue forming complete thin intra-lobular bridging interconnecting with each other divided the parenchyma into separate fragments (Figure 7D). Meanwhile, in both BL 45 and BL 60 groups, livers showed grade 4 fibrosis and the fibrous tissue forming complete thick intra-lobular bridging interconnecting with each other divide the parenchyma into separate fragments with a tendency to form cirrhotic nodules (Figure 7E \& F).

\subsubsection{Fibrosis score}

The mean \pm SD of liver fibrosis scores of BL rats (Figure 8 and Table 2), were increased gradually until day 60 to be 5.8 \pm 0.4 (periportal fibrosis $=3.8 \pm 0.4$ and perisinusoidal fibrosis $=2.0 \pm 0.0$ ). Periportal fibrosis was noticed as early as 10 days, while the perisinusoidal fibrosis was first noticeable at 20 days. The maximum significant increase in the periportal fibrosis started at group BL30 while the maximum significant increase in the perisinusoidal fibrosis started at group $B L 45$. 


\section{DISCUSSION}

Cholestatic liver injury is one of the major causative factors for the development of liver fibrosis or even cirrhosis [9]. Consequently, the progressive increasing knowledge about hepa tocyte and cholangiocyte transport systems will permit a better understanding of the pathogenesis of cholestasis. Therefore, researchers are working hard to understand the pathophysiology of ongoing hepatic fibrosis and to improve the diagnostic workup of such disease. For many years, ligation of the common bile duct has been carried out $[20,21]$ and has been-established experimental liver injury model. However, most of these earlier studies in rodents allowed animals to be kept for short times because ma ny complications and obstacles were frequently observed. As a result, several trials and studies were directed towards developing a reproducible protocol with fewer complications and high satisfaction for investigating ongoing hepatic insults due to cholestasis.

In the present study, the routine protocol for induction of obstructive cholestasis was applied typically except in approaching the common bile duct, where two techniques were used. Al though Tag et al [3] mentioned that BL surgery must be performed by an experienced hepatological scientist, nevertheless, it results in significant va riations, complications and high mortality. The Stomach approach was operated with non-hepatological surgeon and results in no mortality and significant-high surgeon satisfaction. This could be explained by the easy accessibility of the common bile duct, the minimum manipulation of the liver and the short incisional length. Additionally, in SA the bile duct wasn't separated but be double ligated and transected in situation avoiding the accidental tearing and bleeding of vital portal vein and hepatic artery which is the case in LA.

As early after $\mathrm{BL}$, the inability to excrete bile acids into the canaliculus disrupts the enterohepatic bile acid circulation resulting in elevated both hepatocellular and serum bile acid salts (total bilirubin, direct bilirubin, and indirect bilirubin) concentrations at BL10 to about 4, 7 and 4 folds, respectively, to produce a state of jaundice. Bile acids, the toxic hydrophobic molecules, were considered to represent detergents that caused plasma and intracellular membrane damage [22]. Subsequently, this leads to increased biliary pressure, biliary structural alteration, ductular rupture, and finally necrosis of the hepatocytes accompanied by many chemicals and physical changes and alteration of the secretory, metabolic, and synthetic functions of theliver[23]. Retention and accumulation of bile acids within the liver contribute to a hepatocellular injury sufficient to cause hepatocyte death by triggering the apoptotic machinery [24] manifested by a significant decrease of serum albumin synthesized by hepatocytes and rapidly excreted into the bloodstream, and impairment inbile formation. Therefore serum bile salts after 10 days from BL significantly decreased and signs of jaundice disappeared.
The observed significant delay in wound healing in BL rats could be attributed to jaundice which had been repeatedly recognized as a factor impairing surgical wound healing by many authors [25] and this was explained by a reduction in reticuloendothelial cells and fibroblasts migration, collagen deficiency with rare neova scularization [26], and thus, deficient healing.

Although Piton et al [27] mentioned that ALT is more specific in hepatocellular injury and will become higher than AST, because of its longer plasma half-life. Results of this study showed that AST rose higher than ALT and this could be attributed to the higher activity of AST in hepatocytes [28]. AST: ALT ratio (De Ritis ratio) showed a significant el evation $(>2)$ after BL at all times. AST/ALT ratio has gained much attention in different studies in the diagnosis of acute and chronic liver diseases of various origins as this variable is readily available, inexpensive, easy to interpret, and its clinical utilityi s quite promising [29]. Normal AST: ALT ratio is $<1$ [29] and when associated with an intrahepatic cholestatic picture, it will be $>1.5$ wi th low sensitivity and a specificity of $65-79 \%$ as it can detect chronic liver diseases without any other manifestation of cirrhotic changes of the liver [30].

Serum bile acid concentrations and ALP and GGT activities were noticed to be linearly related. This was explained by Williamson and Chapman [31], in cholestasis with the absence of canalicular secretion and hepatocellular retention of bile acids leading to increased liver ALP synthesis and their release into the sinusoidal bloodstream rather than into bile. Although serum GGT level is more specific to the liver than ALP [32] which may be increased in bone disease, gastrointestinal disease, or during pregnancy, Chand and Thakur [32] ensured that serum GGT has not shown any superiority over ALP in the evaluation of cholestatic liver disease. Hall and Cash [33] confirmed that levels of both ALP and GGT elevated in similar proportions signify a hepatobiliarysource. Our results confirmed that both serum ALT and GGT are complimentary for the diagnosis of cholestatic liver disease.

In the present study, there was a significant increase in the level of tissue MDA, lipid peroxidation indicator, in BL rats. The hydrophobic bile acids disrupted cell membranes and promoted the generation of reactive oxygen species (ROS) that, in turn, oxidatively modify lipids (lipid peroxidation), proteins, and DNA, and eventually cause hepatocyte dysfunction and a poptosis [34]. The liver, as well as many other tissues, has a range of antioxidant defense systems to relieve oxidative stress which contributes to the initiation and progression of liver injury. Oxidative stress may play a $\mathrm{n}$ important role in the pathogenesis of hepatic injury during cholestasis [14]. Although increased oxidative stress, our own resul ts showed a remarkable decrease in SOD, CAT, and GSH which indicated decreased antioxidant barrier efficiency [35].

Liver apoptosis was detected by flow cytometer using fluorescein-labeled Annexin V. which shows a high affinity for 
phosphatidylserine residues in the presence of millimolar concentrations of $\mathrm{Ca} 2$ [36]. Results showed the detrimental effect of bile acids on the hepatocytes by the increase in the levels of Annexin V. These results could be explained as bile acids disrupt cell membranes through their detergent action on lipid components and promote the generation of ROS that eventually cause hepatocyte a poptosis [35]. Apoptotic cells can be discriminated from necrotic cells. These cells become Annexin V-positive because of its binding to PS at the cytoplasmic side of the plasma membrane [35].

After bile duct ligation, there were significant increases in the level of TGF- $\beta$ in a direct correlation to the dura tion of bile duct ligation. TGF- $\beta$ has multiple profibrogenic, antiinflammatory, and immunosuppressive effects. The balance of these actions is required for maintaining tissue homeostasis. Moreover, TGF- $\beta$ is an important negative regula tor of proliferation and an inducer of apoptosis [37], and its aberrant expression is involved in a number of disease processes in the liver [38]. In this study, histopathological examination and fibrosis scores confirmed our results of TGF$\beta$ which is a master profibrogenic cytokine and mi lestones on pathway related to liver fibrosis, HSCs activation and transdifferentiation of HSCs into myofibroblasts which are the main producers of collagens and other extracellular matrix proteins and are therefore central in scar formation during liver fibrogenesis [38].

It is concluded that stomachapproach provides an easy, fast and reliable procedure for induction of obstructive cholestasis in rats. Liver Annexin V and TGF- $\beta$ are diagnostic tools in further apoptosis and fibrosis.

\section{Acknowledgment}

Grateful thanks to Dr. Gamal Karrouf, Professor and Head of Surgery, Anaesthiolology and Ra diology Department, Faculty of Veterinary Medicine, Mansoura University for final editing and revision of the manuscript

\section{Conflict of interest statement}

The authors declare that there is noconflict of interest in the current research work.

\section{Research Ethics Committee Permission}

The current research work is permitted to be executed according to standards of Research Ethics committee, Faculty of Veterinary Medicine, Mansoura University.

\section{Authors contribution}

N. E. and A. S. conducted the experiment, analytical procedures, research writing; A.Z. conducted the experiment design, and revised the manuscript; E. M. revised the manuscript.

\section{REFERENCES}

[1] Trauner M, Meier PJ, Boyer JL. Molecular regulation of hepatocellular transport systems in cholestasis. J Hepatol 1999;31:165-78. https://doi.org/10.1016/S0168-8278(99)80179-2
[2] Symeonidis A, Trams EG. Morphologic and functional changes in the livers of rats after ligation or excision of the common bile duct. Am J Pathol 1957;33:13-27.

[3] Tag CG, Weiskirchen S, Hittatiya K, Tacke F, Tolba RH, Weiskirchen R. Induction of experimental obstructive cholestasis in mice. Lab Anim 2015;49:70-80. https://doi.org/10.1177/0023677214567748

[4] Mazumdar B, Meyer K, Ray R. N-terminal region of gelsolin induces apoptosis of activated hepatic stellate cells by a caspase-dependent mechanism. PLoS ONE 2012;7:e44461. https://doi.org/10.1371/journal. pone.0044461

[5] Yanguas SC, Cogliati B, Willebrords J, Maes M, Colle I, van den Bossche $B$, et al. Experimental models of liver fibrosis. Arch Toxicol 2016;90:1025-48. https://doi.org/10.1007/s00204-015-1543-4

[6] Tag CG, Sauer-Lehnen S, Weiskirchen S, Borkham-Kamphorst E, Tolba $\mathrm{RH}$, Tacke $\mathrm{F}$, et al. Bile duct ligation in mice: induction of inflammatory liver injury and fibrosis by obstructive cholestasis. J Vis Exp 2015. https://doi.org/10.3791/52438

[7] Wang K, Lin B. Pathophysiological Significance of Hepatic Apoptosis. ISRN Hepatology 2013;2013:740149 https://doi.org/10.1155/2013/740149

[8] Cujic D, Golubovic S, Bojic-Trbojevic Z, Ilic N, Nedic O. Differential diagnosis of liver diseases using serum biomarkers. Journal of BUON Official Journal of the Balkan Union of Oncology 2010.

[9] Liedtke C, Luedde T, Sauerbruch T, Scholten D, Streetz K, Tacke F, et al. Experimental liver fibrosis research: update on animal models, legal issues and translational aspects. Fibrogenesis Tissue Repair 2013;6:19. https://doi.org/10.1186/1755-1536-6-19

[10] Emre $M H$, Polat $A$, Eşrefoğlu $M$, Karabulut $A B$, Gül M. Effects of melatonin and acetylsalicylic acid against hepatic oxidative stress after bile duct ligation in rat. Acta Physiologica Hungarica 2009. https://doi. org/10.1556/APhysiol.2008.0001

[11] Ding $Q$, Xie X-L, Wang $M-M$, Yin J, Tian J-M, Jiang X-Y, et al. The role of the apoptosis-related protein BCL-B in the regulation of mitophagy in hepatic stellate cells during the regression of liver fibrosis. ExpMol Med 2019;51:6. https://doi.org/10.1038/s12276-018-0199-6

[12] Seki E, Brenner DA. Recent advancement of molecular mechanisms of liver fibrosis. J HepatobiliaryPancreatSci 2015;22:512-8. https://doi.org/10.1002/jhbp.245

[13] Meers $P$, Mealy T. Phospholipid determinants for annexin $V$ binding sites and the role of tryptophan 187. Biochemistry 1994;33:5829-37. doi:10.1021/bi00185a022. https://doi.org/10.1021/bi00185a022

[14] Sokol RJ, Devereaux M, Khandwala RA. Effect of dietary lipid and vitamin $E$ on mitochondrial lipid peroxidation and hepatic injury in the bile duct-ligated rat. J Lipid Res 1991;32:1349-57.

[15] Koopman G, Reutelingsperger CP, Kuijten GA, Keehnen RM, Pals ST, van Oers $\mathrm{MH}$. Annexin $\mathrm{V}$ for flow cytometric detection of phosphatidylserine expression on B cells undergoing apoptosis. Blood 1994;84:1415-20. https://doi.org/10.1182/blood.V84.5.1415. bloodjournal8451415

[16] Vermes I, Beishuizen A, Hampsink RM, Haanen C. Dissociation of plasma adrenocorticotropin and cortisol levels in critically ill patients: possible role of endothelin and atrial natriuretic hormone. J ClinEndocrinolMetab https://doi.org/10.1210/jcem.80.4.7714094 1995;80:1238-42.

[17] Yokoyama H, Masaki T, Inoue I, Nakamura M, Mezaki Y, Saeki C, et al. Histological and biochemical evaluation of transforming growth factor- $\beta$ activation and its clinical significance in patients with chronic liver disease. Heliyon 2019;5:e01231. https://doi.org/10.1016/j.heliyon.2019.e01231

[18] Krishna M. Role of special stains in diagnostic liver pathology. Clin Liver Dis (Hoboken) 2013;2:S8-10. https://doi.org/10.1002/cld.148 
[19] Huss S, Schmitz J, Goltz D, Fischer H-P, Büttner R, Weiskirchen R. Development and evaluation of an open source Delphi-based software for morphometric quantification of liver fibrosis. Fibrogenesis Tissue Repair 2010;3:10. https://doi.org/10.1186/17551536-3-10

[20] Georgiev P, Jochum W, Heinrich S, Jang JH, Nocito A, Dahm F, et al. Characterization of time-related changes after experimental bile duct ligation. Br J Surg 2008;95:646-56. https://doi.org/10.1002/bjs.6050

[21] Heinrich S, Georgiev P, Weber A, Vergopoulos A, Graf R, Clavien P-A. Partial bile duct ligation in mice: a novel model of acute cholestasis. Surgery 2011;149:445-51. https://doi.org/10.1016/j.surg.2010.07.046

[22] Akare S, Martinez JD. Bile acid induces hydrophobicity-dependent membrane alterations. BiochimBiophysActa 2005;1735:59-67. doi:10.1016/j.bbalip.2005.04.006. https://doi.org/10.1016/j. bbalip.2005.04.006

[23] Cannon MV, Pilarowski G, Liu X, Serre D. Extensive epigenetic changes accompany terminal differentiation of mouse hepatocytes after birth. G3 (Bethesda) 2016;6:3701-9. https://doi.org/10.1534/g3.116.034785

[24] Guicciardi ME, Gores GJ. Bile acid-mediated hepatocyte apoptosis and cholestatic liver disease. Dig Liver Dis 2002;34:387-92. https://doi.org/10.1016/S1590-8658(02)80033-0

[25] Ivin TT, Vassilakis JS, Chattopadhyay DK, Greaney MG. Abdominal wound healing in jaundiced patients. Br J Surg 1978;65:521-2. https://doi.org/10.1002/bjs.1800650722

[26] Dawiskiba J, Kwiatkowska D, Zimecki M, Kornafel P, Tyran W, Czapińska $E$, et al. The impairment of wound healing process is correlated with abnormalities of TNF-alpha production by peritoneal exudate cells in obstructive jaundiced rats. HPB Surg 2000;11:311-8. https://doi.org/10.1155/2000/82905

[27] Piton A, Poynard T, Imbert-Bismut F, Khali L, Delattre J, Pelissier E, et al. Factors associated with serum alanine transaminase activity in healthy subjects: consequences for the definition of normal values, for selection of blood donors, and for patients with chronic hepatitis C. MULTIVIRC Group. Hepatology 1998;27:1213-9. https://doi.org/10.1002/hep.510270505

[28] Sheth SG, Flamm SL, Gordon FD, Chopra S. AST/ALT ratio predicts cirrhosis in patients with chronic hepatitis $\mathrm{C}$ virus infection. Am J Gastroenterol 1998;93:44-8. https://doi.org/10.1111/j.15720241.1998.044_c.x

[29] Karim SMF, Rahman MR, Shermin S, Sultana R. Correlation between Aminotransferase Ratio (AST/ALT) and Other Biochemical Parameters in Chronic Liver Disease of Viral Origin. Delta Med Col J 2015;3. https://doi. org/10.3329/dmcj.v3i1.22234

[30] Alempijevic T, Krstic M, Jesic R, Jovanovic I, SokicMilutinovic A, Kovacevic $\mathrm{N}$, et al. Biochemical markers for non-invasive assessment of disease stage in patients with primary biliary cirrhosis. World J Gastroenterol 2009;15:591-4. https://doi.org/10.3748/wjg.15.591

[31] Williamson KD, Chapman RW. Editorial: further evidence for the role of serum alkaline phosphatase as a useful surrogate marker of prognosis in PSC. Aliment PharmacolTher 2015;41:149-51. https://doi.org/10.1111/apt.13004

[32] Chand K, Thakur S. "Significance of serum gamma glutamyltranspeptidase in cholestatic jaundice". Indian J Med Sci 1997; 51:270-4.

[33] Hall P, Cash J. What is the real function of the liver "function" tests? Ulster Med J 2012;81:30-6.

[34] Jusman SAWA, Halim A. Oxidative stress in liver tissue of rat induce d by chronic systemic hypoxia. MJHR 2010;13. https://doi.org/10.7454/msk.v13i1.346
[35] Bindhumol V, Chitra KC, Mathur PP. Bisphenol A induces reactive oxygen species generation in the liver of male rats. Toxicology 2003;188:117-24. https://doi.org/10.1016/S0300-483X(03)00056-8

[36] Zhou $\mathrm{Y}$, Wang $\mathrm{P}$, Xiong J, Yue H, He $\mathrm{Y}$, Ouyang $\mathrm{H}$, et al. A label-free strategy for measuring the affinity between monoclonal antibody and hapten using microdialysis sampling combined with chemiluminescent detection. BiosensBioelectron 2017;87:404-9. https://doi.org/10.1016/j. bios.2016.08.068

[37] Zhao Y-L, Zhu R-T, Sun Y-L. Epithelial-mesenchymal transition in liver fibrosis. Biomed Rep 2016;4:269-74. https://doi.org/10.3892/br.2016.578

[38] Dewidar B, Meyer C, Dooley S, Meindl-Beinker AN. TGF- $\beta$ in Hepatic Stellate Cell Activation and Liver Fibrogenesis-Updated 2019. Cells 2019;8. https://doi.org/10.3390/cells8111419 